\title{
The Role of Water During the Crystallization of Amorphous Cobalt Phosphate Nanoparticles
}

\author{
Sven Bach, ${ }^{\dagger, \S}$ Martin Panthöfer, ${ }^{\dagger}$ Ralf Bienert, ${ }^{\$}$ Ana de Oliveira Guilherme Buzanich, ${ }^{\$}$ Franziska \\ Emmerling, ${ }^{\$}$ and Wolfgang Tremel ${ }^{\dagger,{ }^{*}}$ \\ ${ }^{\dagger}$ Institute of Inorganic Chemistry and Analytical Chemistry, Johannes Gutenberg University Mainz, Duesbergweg 10- \\ 14, D-55128 Mainz, Germany \\ ${ }^{\S}$ Graduate School Materials Science in Mainz, Staudinger Weg 9, D-55128 Mainz, Germany \\ ${ }^{\$}$ Federal Institute for Materials Research and Testing, Richard-Willstätter-Straße 11, D-12489 Berlin, Germany
}

\section{Electronic Supplementary Information (ESI)}

Section $S_{1}$ - Experimental Details

Section S2 - Additional Figures and Tables:

Figure S2 EDX spectrum of RT-ACP

Figure $\mathrm{S}_{3}$ Possible pre-peak transitions for $\mathrm{Co}_{3}\left(\mathrm{PO}_{4}\right)_{2} \times 8 \mathrm{H}_{2} \mathrm{O}$

Figure $\mathrm{S}_{4}$ SEM image of RT-ACP

Figure $\mathrm{S}_{5} \mathrm{SAXS}$ data of RT-ACP

Figure S6 DTA/TGA of $\mathrm{Co}_{3}\left(\mathrm{PO}_{4}\right)_{2} \times 8 \mathrm{H}_{2} \mathrm{O}$

Figure $\mathrm{S}_{7} \mathrm{SEM}$ image of $\mathrm{Co}_{3}\left(\mathrm{PO}_{4}\right)_{2}$

Figure S8 IR spectrum of $\mathrm{Co}_{3}\left(\mathrm{PO}_{4}\right)_{2}$ after different treatments

Figure S9 DTA/TGA of HT-ACP

Figure S1o Standards for quantification of the different cobalt phosphate hydrates (splitting of the asymmetric stretching mode)

Figure S11 Standards for quantification of the different cobalt phosphate hydrates (extinction of symmetric stretching mode)

Table S1 Results of ICP-MS and ICP-OES measurements

Table S2 Results of IR spectroscopy in detail

Section $\mathrm{S}_{3}$ - Fitting EXAFS data with ARTEMIS 


\section{Section S1 - Experimental Details:}

Scanning electron microscopy (SEM) was performed with a Zeiss Gemini Supra 40 (samples sputtered with carbon, acceleration voltage $15 \mathrm{kV}$, working distance $2.8 \mathrm{~mm}$ ). Transmission electron microscopy (TEM) was carried out on a Philips EM-420 device. The samples were prepared on a carbon-coated copper grid and vacuum dried at room temperature, acceleration voltage $120 \mathrm{kV}$. Energydispersive X-ray analysis (EDX) was performed with a Bruker Quantax 400 device mounted at the Zeiss SEM.

For ICP-MS measurements, a precisely weighed amount of ACP was solubilized with $5 \mathrm{~mL}$ sub-boiled conc. $\mathrm{HNO}_{3}$ in a Teflon vessel by a microwave digestion. The digestion solution was filled up to $100 \mathrm{~mL}$ with deionized water and subsequently diluted with $3.3 \% \mathrm{HNO}_{3} 1$ to 1000 . Blanc values for $5 \mathrm{~mL}$ conc. $\mathrm{HNO}_{3}$ filled up to $100 \mathrm{~mL}$ with deionized water were subtracted. The measurements were performed on an ICP-sector field-MS device - Thermo element 2 (Thermo Scientific, Bremen, Germany) (medium resolution $\mathrm{R}=4500$ ). The sample was conducted to the ICP-SF-MS by a PFA nebulizer (gas flow: $1.22 \mathrm{~L} \mathrm{~min}^{-1}$, cooling gas: $16 \mathrm{~L} \mathrm{~min}^{-1}$ ) through a Peltier-cooled PFA-cyclone-spray chamber $\mathrm{PC}^{3}\left(4^{\circ} \mathrm{C}\right)$ (Elemental Scientific Inc., Omaha, NE, USA). The sample were analyzed ten times for $70 \mathrm{~s}$ with a dwell time of $10 \mathrm{~s}$. Quantification was performed with external calibration (standard solutions prepared with $3.3 \% \mathrm{HNO}_{3}$ ).

X-ray Diffraction. X-ray powder diffraction (XRD) measurements were conducted with a STOE Stadi-P equipped with a Mythen Dectris Detector using monochromated MoK $\alpha$ radiation $(0.70930 \AA)$ in Debye-Scherrer geometry. The measuring circle radius was $275 \mathrm{~mm}$ and the aperture had a distance of $0.3 \mathrm{~mm}$. The width of the irradiated sample was $10 \mathrm{~mm}$. The XRD intensities were collected in a range of 4 to $32^{\circ} 2 \Theta$ with an increment of $0.01^{\circ} 2 \Theta$. Each step was measured for $10 \mathrm{~s}$.

High resolution synchrotron powder diffraction data for ACP were collected using beamline 11-BM at the Advanced Photon Source (APS), Argonne National Laboratory using an average wavelength of $0.413664 \AA$. Discrete detectors covering an angular range from -6 to $16^{\circ} 2 \Theta$ are scanned over a $34^{\circ} 2 \Theta$ range, with data points collected every $0.001^{\circ} 2 \Theta$ and scan speed of $0.01^{\circ} / \mathrm{s}$. The 11-BM instrument uses x-ray optics with two platinum-striped mirrors and a double-crystal $\mathrm{Si}(111)$ monochromator, where the second crystal has an adjustable sagittal bend. Ion chambers monitor incident flux. A vertical Huber 480 goniometer, equipped with a Heidenhain encoder, positions an analyzer system comprised of twelve perfect $\mathrm{Si}(111)$ analyzers and twelve Oxford-Danfysik $\mathrm{LaCl}_{3}$ scintillators, with a spacing of $2^{\circ} 2 \Theta$. Analyzer orientation can be adjusted individually on two axes. A three-axis translation stage holds the sample mounting and allows it to be spun, typically at $\sim 5400 \mathrm{rpm}(90 \mathrm{~Hz})$. A Mitsubishi robotic arm is used to mount and dismount samples on the diffractometer. ${ }^{\mathrm{S} 1}$ An Oxford Cryosystems Cryostream Plus device allows sample temperatures to be controlled over the range $80-500 \mathrm{~K}$ when the robot is used. The diffractometer is controlled via EPICS. ${ }^{\mathrm{S} 2}$ Data were collected while continually scanning the diffractometer $2 \Theta$ arm. A mixture of NIST standard reference materials, $\mathrm{Si}$ (SRM 640c) and $\mathrm{Al}_{2} \mathrm{O}_{3}(\mathrm{SRM}$ 676) is used to calibrate the instrument, where the Si lattice constant determines the wavelength for each detector. Corrections are applied for detector sensitivity, $2 \Theta$ offset, small differences in wavelength between detectors, and the source intensity, as noted by the ion chamber before merging the data into a single set of intensities evenly spaced in $2 \Theta$.

Small Angle X-ray Scattering. For small-angle X-ray measurement, ACP was dispersed in water-free ethanol and treated with a sonication probe (Diameter $7 \mathrm{~mm}$, max. amplitude $175 \mu \mathrm{m}$, acoustic power density $300 \mathrm{~W} / \mathrm{cm} 2$ ) for 15 minutes. Measurements were performed with a SAXSess device of Anton Paar using monochromated CuKa radiation and a CCD camera (SCX-TE: 4300K/2; Pixel size: $24 \times 24 \mu \mathrm{m}^{2}$ ) at $23.6^{\circ} \mathrm{C}$.

Differential Scanning Microscopy. Differential thermal analysis (DTA) and thermogravimetric analysis (TGA) were carried out on a Netzsch STA 449 F3 Jupiter. The samples were deposited in an ALOX crucible and heated from 20 to $700^{\circ} \mathrm{C}$ under an argon flow. The heating rate was $10 \mathrm{~K} \mathrm{~min}^{-1}$ and the flow rate was $10 \mathrm{~mL} \mathrm{~min}^{-1}$.

Infrared spectroscopy. Fourier-transform infrared (FT-IR) spectra were measured with a Bruker Alpha-P FT-IR spectrometer with platinum ATR; the spectra were recorded 64 times and the resolution was $4 \mathrm{~cm}^{-1}$.

Optical Spectroscopy. UV-Vis spectra were recorded with a Cary 5 G UV-Vis-NIR spectrophotometer equipped with an Ulbricht sphere. The solid phosphates were fixed with a scotch tape and the diffuse reflectance of the samples was measured in the range of 400 to $800 \mathrm{~nm}$ with a scan rate of $1 \mathrm{~nm} / \mathrm{s}$. The spectra were corrected by subtraction of the scotch tape background.

$X$-ray absorption spectroscopy. XANES and EXAFS measurements were performed at the BAMline (BESSY-II) at the Co-K edge $(7709 \mathrm{eV})$ in transmission, according to the sketch below (Figure S1).

All samples were measured four times and merged in $\mu(\mathrm{E})$ to increase signal to noise ratio. For data analysis and evaluation, the open source software packages Athena and Artemis based on IFEFFIT were used ${ }^{\mathrm{S3}}$ For background subtraction the Rbkg value was set to 1.0. All spectra were normalized to the post-edge region, free from absorption features. A Hanning-type Fourier window for

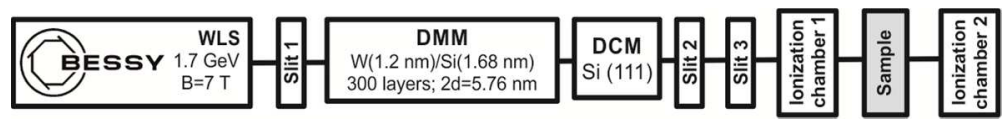

Figure S1. Schematics of the experiments for XANES/EXAFS in transmission.

forward Fourier transform was set to the $k$-range between 1-7.5 $\AA^{-1}$ with a dk value of 1.0. Furthermore, a crystal identification file (CIF) from $\mathrm{Co}_{3}\left(\mathrm{PO}_{4}\right)_{2} \times 8 \mathrm{H}_{2} \mathrm{O}$ was used for simulation, using FEFF, under Artemis, as a comparison basis and fitted to the experimental EXAFS spectra. 
Density measurements. The density of the amorphous sample was determined by AccuPyc 1330 He pycnometer (Micrometrics $\mathrm{GmbH}$ ). The measuring volume of $100 \mathrm{~cm}^{3}$ was decreased to $50 \mathrm{~cm}^{3}$ by a stainless steel calibration sphere. We measured the sample 25 times in order to get a low standard deviation.

(S1) Lee, P. L.; Shu, D.; Ramanathan, M.; Preissner, C.; Wang, J.; Beno, M. A.; von Dreele, R. B.; Ribaud, L.; Kurtz, C.; Antao, S. M.; Jiao, X.; Toby, B. H. J. Synchr. Rad. 2oo8, 15, 427-432.

(S2) Dalesio, L. R.; Hill, J. O.; Kraimer, M.; Lewis, S.; Murray, D.; Hunt, S.; Watson, W.; Clausen, M.; Dalesio, J. Nucl. Instrum. Methods Phys. Res., Sect. A 1994, 352, 179-184.

(S3) Newville, M.; Ravel, B. J. Synchrotron Rad. 2005, 12, 537-541. 
Section S2 - Additional Figures and Tables

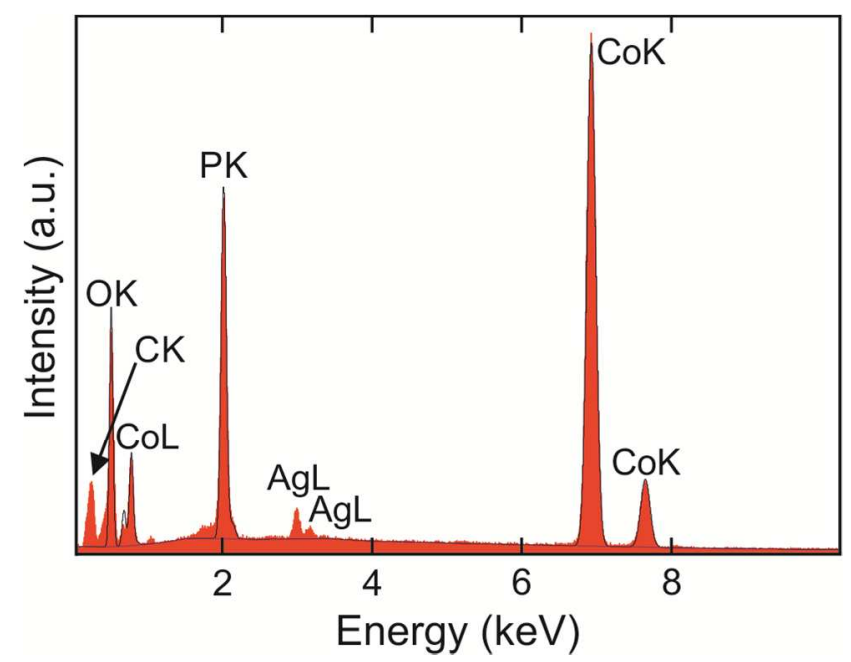

(Figure S2) Energy dispersive X-ray spectrum of ACP. 


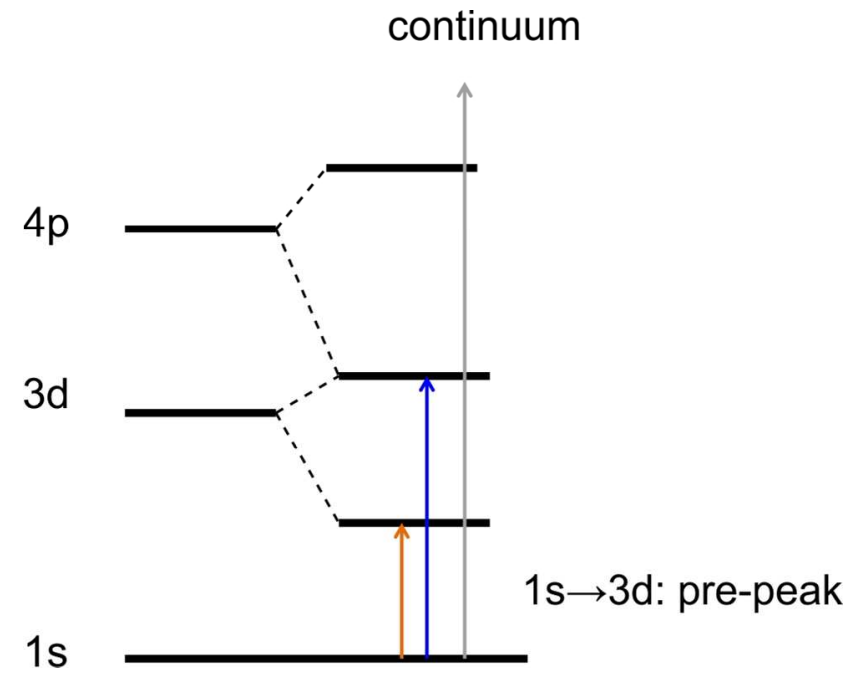

(Figure $S_{3}$ ) Possible pre-peak transitions for $\mathrm{Co}_{3}\left(\mathrm{PO}_{4}\right)_{2} \times 8 \mathrm{H}_{2} \mathrm{O}$ 


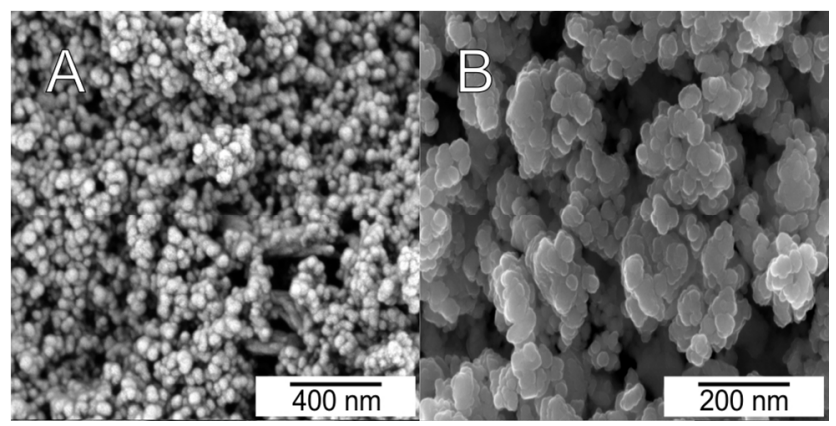

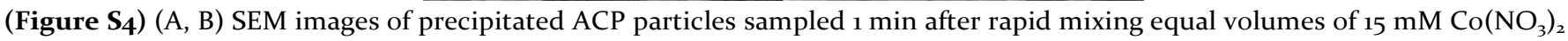
and $10 \mathrm{mM} \mathrm{Na}_{3} \mathrm{PO}_{4}$ solutions. 


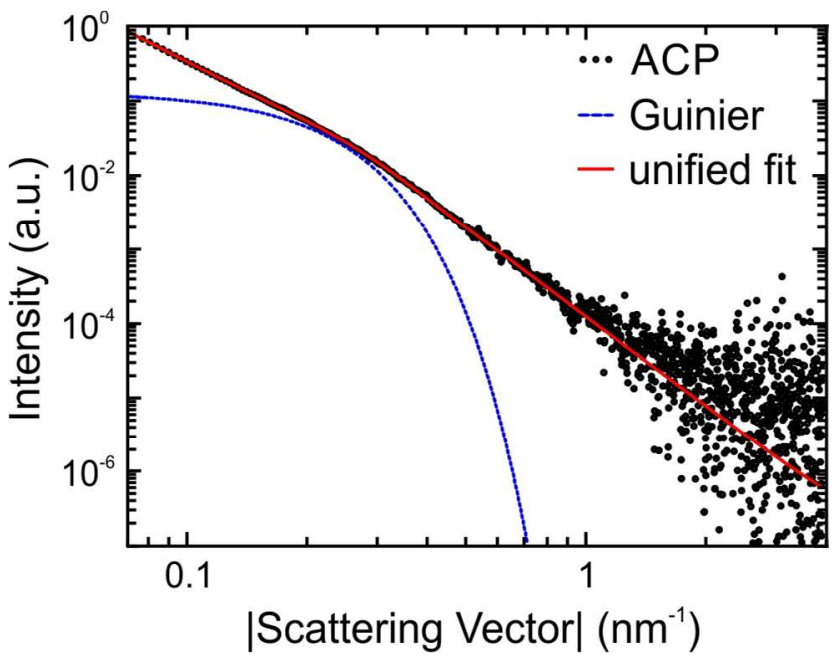

(Figure S5) Scattering curve of ACP (black circles). The SAXS curve was fitted using a unified fit model with two levels (red line). The blue line indicates the Guinier fit.

By dispersing ACP in water-free ethanol and treating with a sonication probe, only a small fraction of aggregates could be disrupted. This is manifested in the scattering curve (Figure S2) that shows in the small q-range an increase in intensity. Furthermore, the sample seems to be highly polydispers or agglomerated. For fitting the scattering curve, a unified fit model was used. In the high q-range a Porod law slope of 4 was determined, indicating the presence of solid particles. From the kinked region the radius of gyration can be deduced according to $\mathrm{I}(\mathrm{q})=\mathrm{I}_{0} \mathrm{e}^{-\frac{\mathrm{g}}{3} \mathrm{q}^{2}}$. Assuming spherical particles, the average diameter can be calculated by $\mathrm{D}=2 \sqrt{5} / 3 \mathrm{R}_{\mathrm{g}}$

For CP a radius of gyration of $9.5 \mathrm{~nm}$ was calculated, resulting in an average diameter of $24.5 \mathrm{~nm}$. 


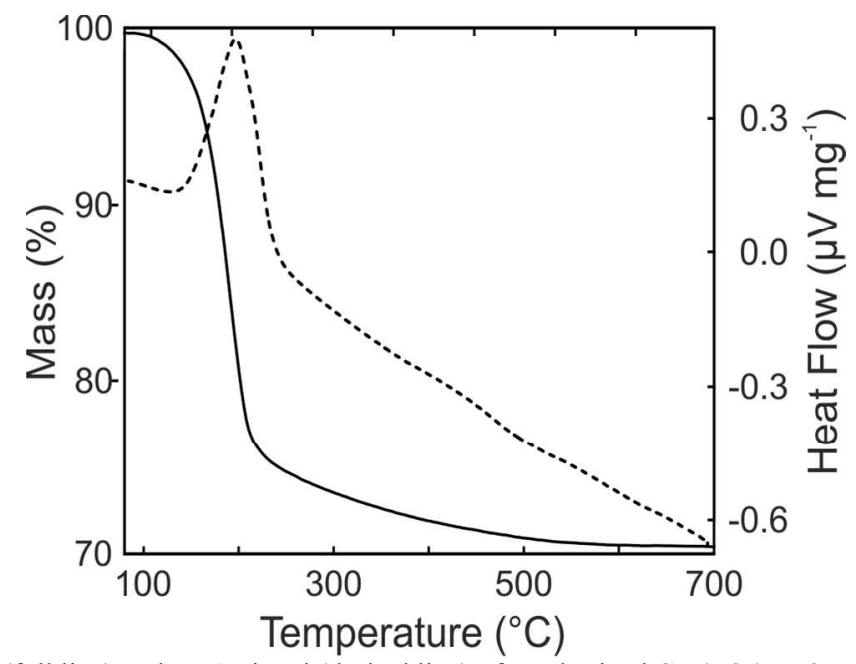

(Figure S6) Thermogravimetric trace (full line) and DTA signal (dashed line) of synthesized $\mathrm{Co}_{3}\left(\mathrm{PO}_{4}\right)_{2} \times 8 \mathrm{H}_{2} \mathrm{O}$ under argon. 


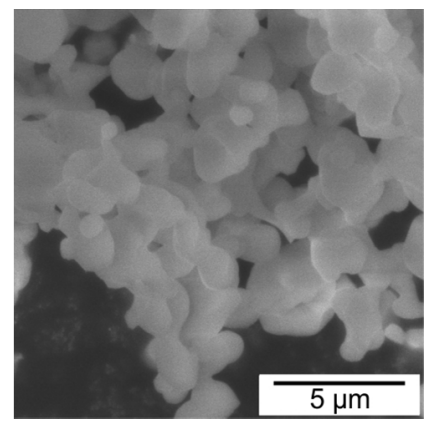

(Figure S7) SEM image of $\mathrm{Co}_{3}\left(\mathrm{PO}_{4}\right)_{2}$ synthesized by heating up RT-AZP one week at $600{ }^{\circ} \mathrm{C}$ under argon. 


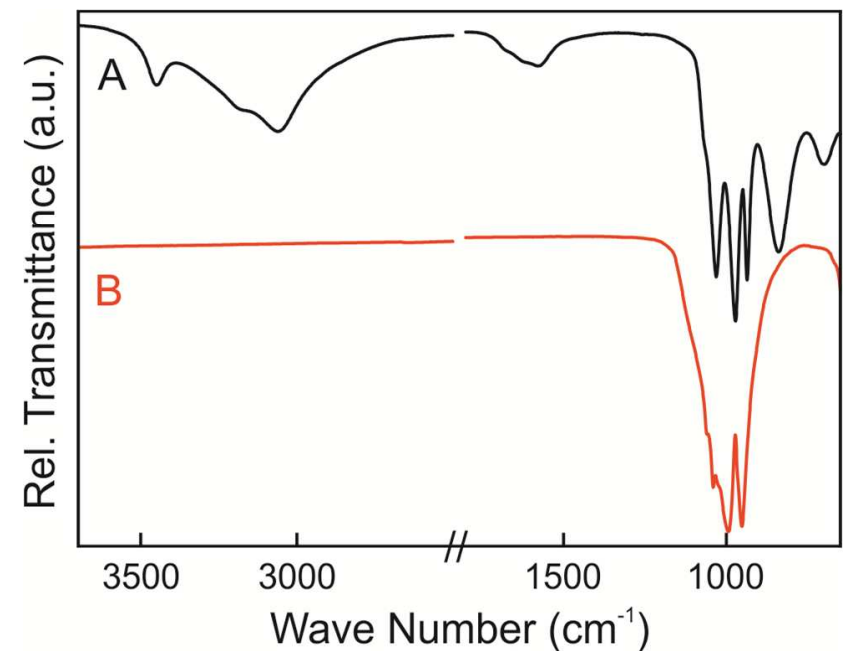

(Figure S8) IR spectrum of $\mathrm{Co}_{3}\left(\mathrm{PO}_{4}\right)_{2}$ after (A) stirring $10 \mathrm{~d}$ in water and (B) under ambient conditions for 2 a. 


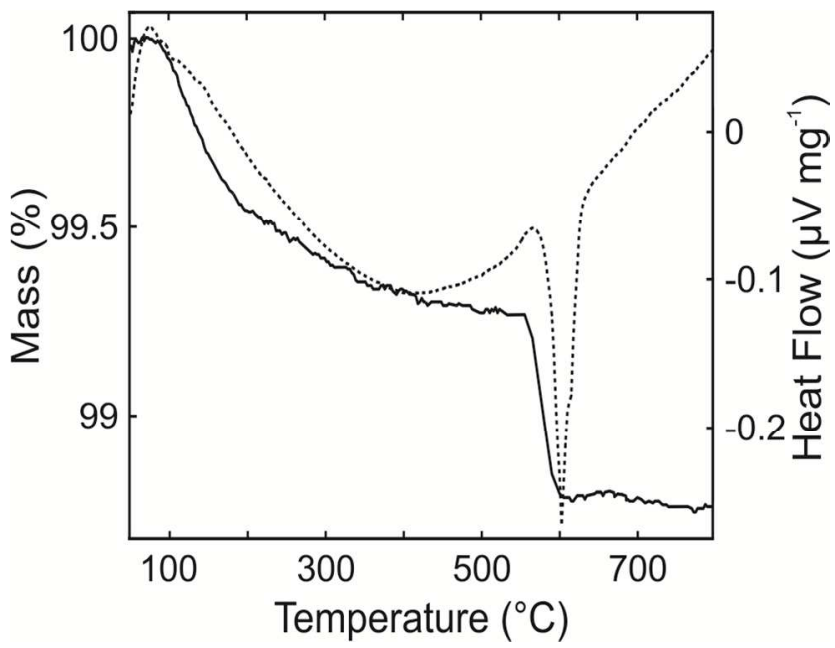

(Figure S9) Thermogravimetric trace (full line) and DTA signal (dashed line) of synthesized HT-ACP under argon. The water loss of $0.51 \%$ at around $600{ }^{\circ} \mathrm{C}$ leads in crystallization of HT-ACP to $\mathrm{Co}_{3}\left(\mathrm{PO}_{4}\right)_{2}$ showing that a completely anhydrous ACP cannot be synthesized. Quantitative analysis results in a composition of $\mathrm{Co}_{3}\left(\mathrm{PO}_{4}\right)_{2} \times 0.25 \mathrm{H}_{2} \mathrm{O}$ for $\mathrm{HT}-\mathrm{ACP}$. 


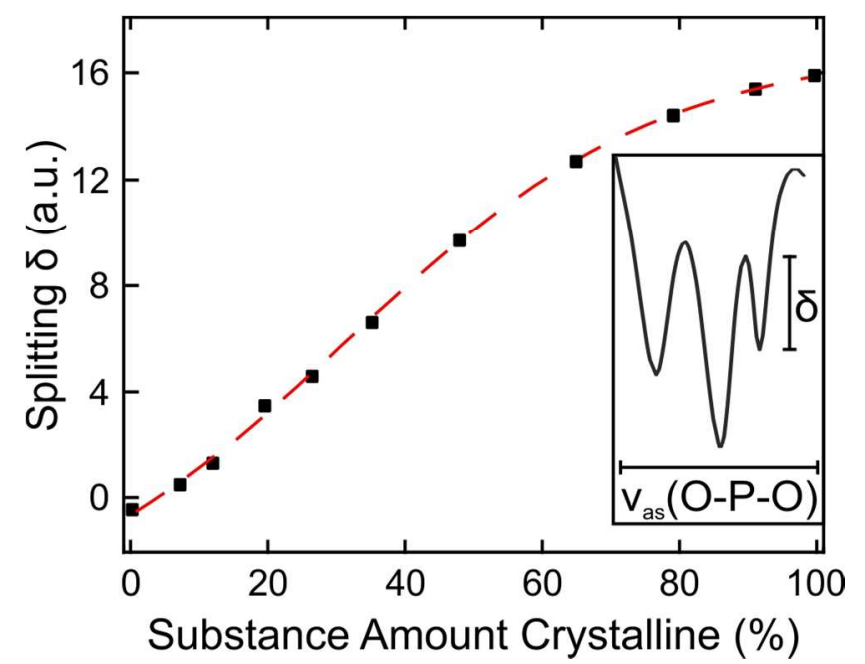

(Figure S10) Standards for quantification: Mixtures of crystalline and amorphous phases of cobalt phosphate hydrate and resulting splitting $\delta$ of the asymmetric phosphate stretching mode (see inset). 


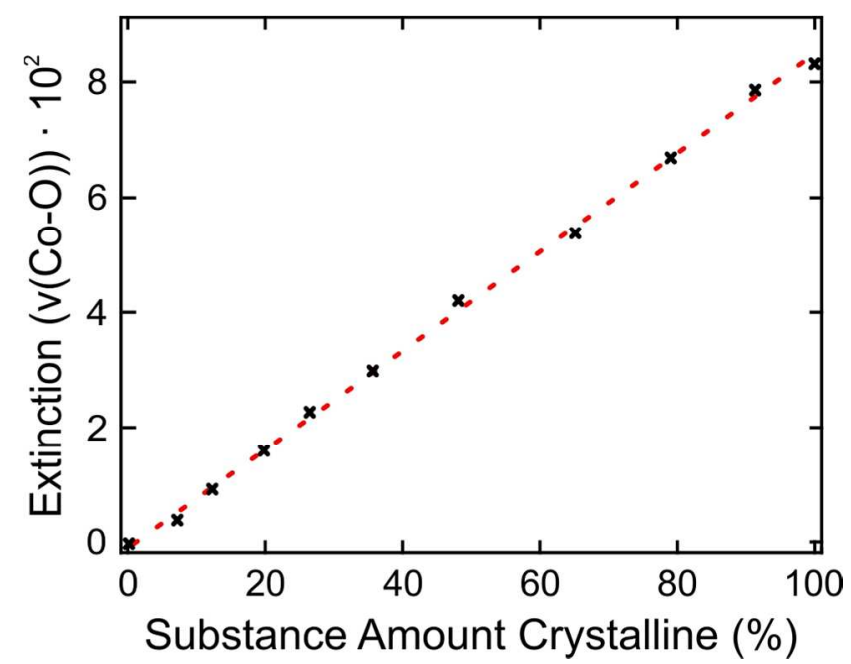

(Figure S11) Standards for quantification: Mixtures of crystalline and amorphous phases of cobalt phosphate hydrate and resulting symmetric stretching modes measured by IR spectroscopy. 
(Table S1) Results of ICP-MS and ICP-OES measurements of ACP. ${ }^{\mathrm{a}}$

\begin{tabular}{lll}
\hline ICP-MS & ${ }^{59} \mathrm{Co}$ & ${ }^{31} \mathrm{P}$ \\
mean conc. $\left(\mu \mathrm{g} \mathrm{L}^{-1}\right)$ & $99.4 \pm 3.4$ & $33.6 \pm 0.7$ \\
mean conc. $\left(\mu \mathrm{mol} \mathrm{L}^{-1}\right)$ & $1.68 \pm 0.06$ & $1.08 \pm 0.02$ \\
Ratio & 3.00 & 1.93 \\
ICP-OES & $\mathrm{Co}$ & $\mathrm{P}$ \\
mean conc. $\left(\mu \mathrm{g} \mathrm{L}^{-1}\right)$ & 102 & 36 \\
mean conc. $\left(\mu \mathrm{mol} \mathrm{L}^{-1}\right)$ & 1.7 & 1.2 \\
Ratio & 3.0 & 2.1 \\
\hline
\end{tabular}

${ }^{\text {a }}$ Average concentrations $\left(\mu \mathrm{g} \mathrm{L}^{-1}\right)$ and standard deviations for Co and $\mathrm{P}$ in $25.7 \mathrm{mg} \mathrm{ACP}$; relative standard deviation of all the samples (RSD) are included. 
(Table S2) Results of IR spectroscopy in detail (all values in $\mathrm{cm}^{-1}$ )

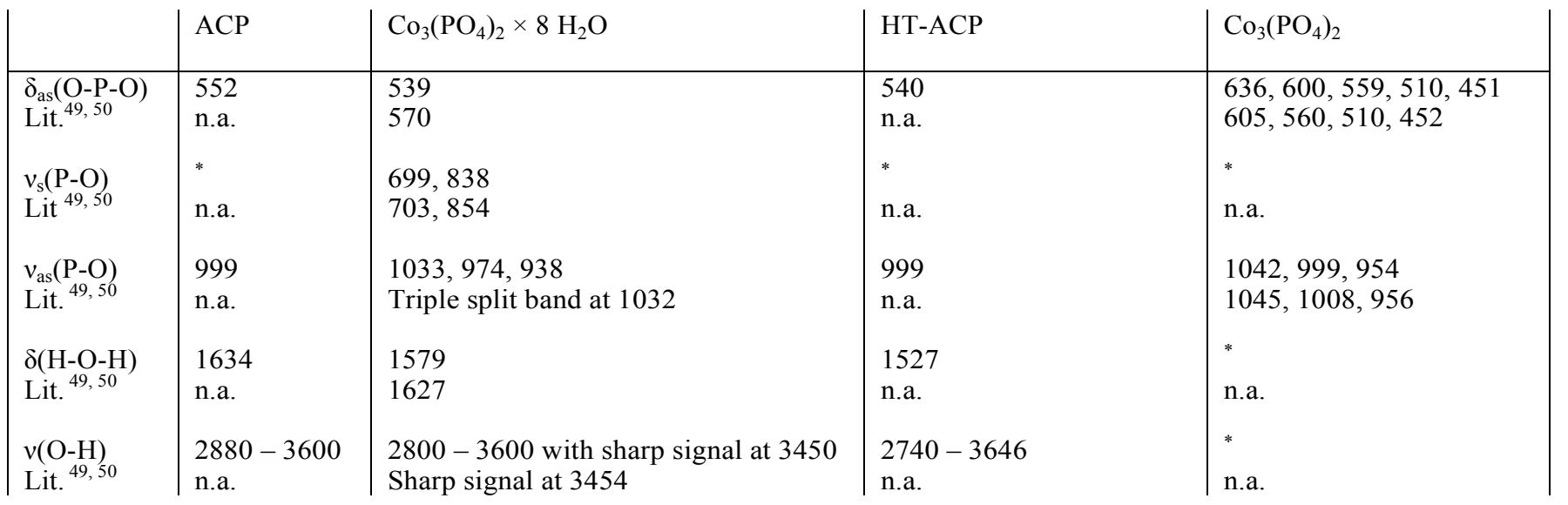

n.a. - no data available

* - do not occur in spectrum 


\section{Section S3 - Fitting EXAFS data with ARTEMIS ${ }^{54}$}

In this procedure the crystallographic data from known molecules (CIF files) with structure similar to the experimentally analyzed are fitted together. The molecule which is closest to the one from the measured sample gives the best fitting results (table 2), which are the reduced-chi ${ }^{2}$ and the $\mathrm{R}$-factor (the smaller the better).

Figure S12 shows the measured spectrum of the crystalline substance $\left(\mathrm{Co}_{3}\left(\mathrm{PO}_{4}\right)_{2} \times 8 \mathrm{H}_{2} \mathrm{O}\right)$ together with its fit results. We used theoretically simulated compounds based on the CIF files "octahydrat_65687" (fit 1, black line) and " $\mathrm{Co}_{3}\left(\mathrm{PO}_{4}\right)_{2}-8 \mathrm{H}_{2} \mathrm{O}$ " (fit 2 , red line).

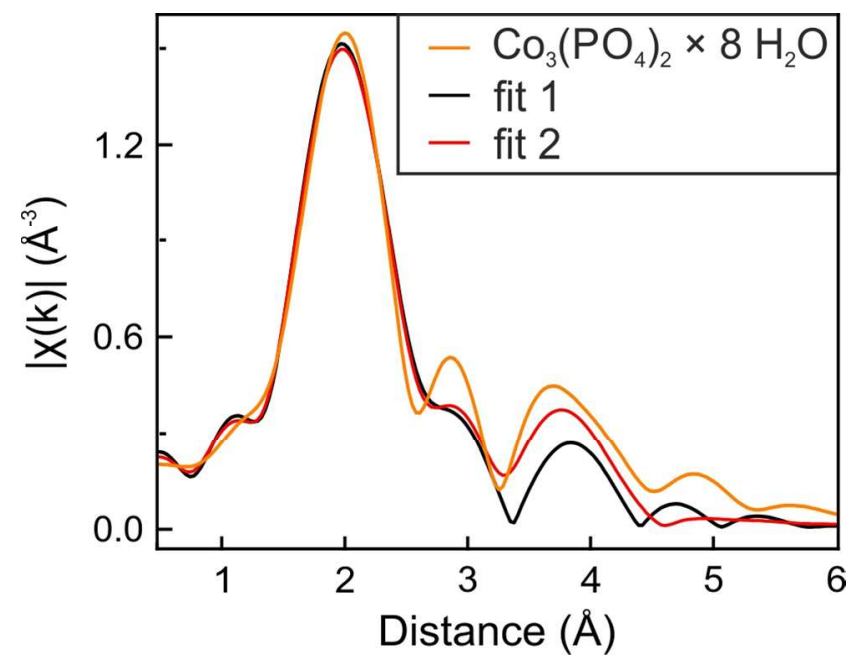

Figure S12. EXAFS signal from $\mathrm{Co}_{3}\left(\mathrm{PO}_{4}\right)_{2} \times 8 \mathrm{H}_{2} \mathrm{O}$ (orange line) together with FIT results from both octahydrate molecules.

Table S3. Quality of fits.

\begin{tabular}{|l|l|l|l|}
\hline fit\# & simulated compound & R-factor & $\begin{array}{l}\text { Red- } \\
\text { chi }\end{array}$ \\
\hline 1 & "octahydrat_65687" & 0.0 .192 & 3907 \\
\hline 2 & "Co $\left(\mathrm{PO}_{4}\right)_{2}-\mathrm{H}_{2} \mathrm{O}$ " & 0.0263 & 3463 \\
\hline
\end{tabular}

Table S4. Results of fit 1 and $2 .$.

\begin{tabular}{|l|l|l|l|l|l|l|l|}
\hline \multicolumn{2}{|l|}{ fit 1 } & fit 2 & type & degen. & $\mathrm{r}_{\text {eff }}$ \\
\hline path_name & type & degen. & $\mathrm{r}_{\text {eff }}$ & path_name & $\mathrm{SS}$ & 6 & 2.102 \\
O1.1 & $\mathrm{SS}$ & 2 & 2.021 & $\mathrm{O} 2.1$ & $\mathrm{SS}$ & 4 & 2.934 \\
O4.1 & $\mathrm{SS}$ & 4 & 2.158 & Co2.1 & $\mathrm{SS}$ & 2 & 3.239 \\
H1.1 & $\mathrm{SS}$ & 8 & 2.451 & $\mathrm{P} .1$ & $\mathrm{SS}$ & 2 & 3.349 \\
P1.1 & $\mathrm{SS}$ & 2 & 3.194 & P.2 & dog-leg & 2 & 3.969 \\
O3.1 & $\mathrm{SS}$ & 4 & 3.579 & $\mathrm{H} 2 \mathrm{O} 4.1 \mathrm{O} 4 \mathrm{w} .1 \mathrm{H} 2 \mathrm{O} 4.1$ & & \\
O4.2 & $\mathrm{SS}$ & 8 & 3.949 & & & & \\
H1.2 O4.2 & obtuse-triangle & 16 & 4.013 & & & & \\
\hline
\end{tabular}

Figure S13 shows the molecular structure of both "octahydrat_65687" (a) and "Co3 $\left(\mathrm{PO}_{4}\right)_{2}-8 \mathrm{H}_{2} \mathrm{O}$ ” (b). The atomic distances in each molecule correspond to the ones obtained by the fit (see Table $\mathrm{S}_{3}$ ).

For example: the $\mathrm{R}_{\text {eff }}$ between Co and $\mathrm{O}_{4.1}$ is $2.158 \AA$, which is exactly the distance shown in Figure $\mathrm{S}_{14}$ A between these two atoms. From the results obtained in Figure $\mathrm{S}_{13}$ and Table $\mathrm{S}_{2}$ and $\mathrm{S}_{3}$ one sees that both molecules fit quite well to the analyzed crystalline substance. Probably molecule " $\mathrm{Co}_{3}\left(\mathrm{PO}_{4}\right)_{2}-8 \mathrm{H}_{2} \mathrm{O}$ " fits slightly better than molecule "octahydrat_65687" to the analyzed sample, as it has a lower R-factor. Furthermore, the height of the peaks seen in Figure Si3, correspond to the $\mathrm{CN}$, which is a measure of the degeneracy, i.e, number of scattering paths at that distance. This is also slightly better for " $\mathrm{Co}_{3}\left(\mathrm{PO}_{4}\right)_{2}-8 \mathrm{H}_{2} \mathrm{O}$ " than for "octahydrat_65687". 

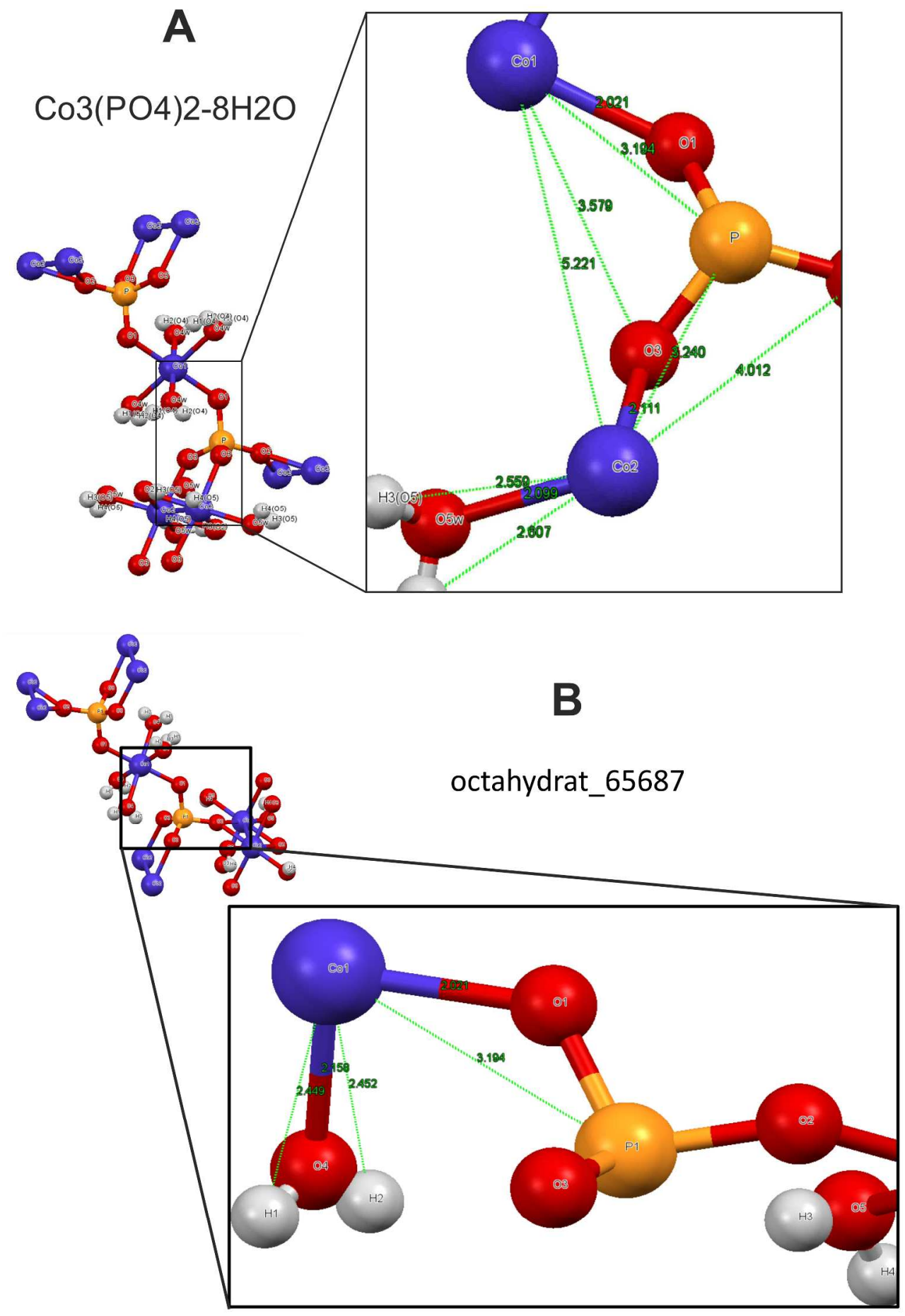

Figure S13. Molecular structure of both “octahydrat_65687" (A) and “ $\mathrm{Co}_{3}\left(\mathrm{PO}_{4}\right)_{2}-8 \mathrm{H}_{2} \mathrm{O}$ ” (B) with atomic distances. 